\title{
Unmet needs for family planning in a municipal area in North Kerala, India
}

\author{
Jesha MM*, Sebastian NM, Sheela P. Haveri, Arya S. Nath
}

Department of Community Medicine, MES Medical College, Perinthalmanna, Kerala, India

Received: 16 May 2016

Accepted: 07 June 2016

\section{*Correspondence:}

Dr. Jesha MM,

E-mail: jesha_ali@yahoo.com

Copyright: (c) the author(s), publisher and licensee Medip Academy. This is an open-access article distributed under the terms of the Creative Commons Attribution Non-Commercial License, which permits unrestricted non-commercial use, distribution, and reproduction in any medium, provided the original work is properly cited.

\section{ABSTRACT}

Background: An important concept to describe effectiveness of family planning programme is unmet need for family planning. Most married women want to limit childbirth and space deliveries but many are unable use contraceptives for varying reasons leading to unmet need. According to national survey in India (NFHS 3), the total unmet need is $13.2 \%$ (unmet need for spacing- 6\% and limiting- 7\%). According to district survey (DLHS 3), in Malappuram district, Kerala, India, the total unmet need was $19.7 \%$ (11.4\% for spacing and $8.3 \%$ for limiting) higher than national unmet need. The objective of this study was to find out unmet need for family planning and its causes and the contraceptive practices among married women of reproductive age group (15-49 years) in Perinthalmanna municipality in northern Kerala, India.

Methods: A cross sectional study was conducted in 35 wards of Perinthalmanna municipality between 8 April to 6 June 2015. The sample size was calculated as 725. From each of the 35 wards, 21 houses were selected randomly and married women in the reproductive age group 15-49 were interviewed using a semi structured questionnaire. Data was analyzed using epi- info version 7.

Results: Among the 753 married women, the total unmet need was 21.2\% (spacing 16.9, limiting 4.3). Among 87 $(11.6 \%)$ currently pregnant women, 66 wanted to conceive, 20 wanted to delay and one didn't want at all. Among the 666 non-pregnant women, 69 were considered in fecund. Among 326 (48.94\%) contraceptive users $26.9 \%$ had undergone sterilization; $47.5 \%$ were using copper T; $13.5 \%$ used condoms and $11.9 \%$ used oral pills. Out of 340 non pregnant women not currently using any contraceptives, $24 \%$ did not want to conceive ever; $27 \%$ wants to conceive but later and $38.8 \%$ were ready to conceive now. Fear of complications, considering it against religious faith, lack of knowledge and partner's opposition were common reasons for not using contraception.

Conclusions: The unmet need for Family Planning is high and in order to reduce the gap, the program should address the above reasons.

Keywords: Family planning, Unmet need, Spacing, Limiting

\section{INTRODUCTION}

India was the first nation in the world to start family planning at the national level in 1951. An important concept which needs addressing in family planning is unmet need for family planning which indicates effectiveness of program. Unmet need for family planning refers to the percentage of fecund women of reproductive age either married or in union, women who either wish to postpone the next birth (spacers) or who wish to stop child bearing (limiters) but are not using a contraceptive method. This clearly indicates a gap between a woman's reproductive intention and current contraceptive behaviour. Unmet need shows how well national family planning programs are achieving the key mission of meeting the population's felt need for family planning. It is a valuable indicator for tracking progress 
towards the target of achieving Universal access to reproductive health.

Over 150 million women worldwide want to delay or avoid pregnancy but are not using family planning methods. ${ }^{1}$ Another study quotes that an estimated 222 million women have unmet need for modern contraception in developing world. ${ }^{2}$ Most of the married women want to use the contraceptive methods but are unable to use because of lack of knowledge, fear of side effects, religious reasons, insufficiency of family planning worker, uncooperative husband and limited supply and high cost.

National family health survey (NFHS) (2005-06) reveals that the unmet need of family planning has declined from $15.8 \%$ in NFHS 2 to $13.2 \%$. $^{3}$ According to NFHS 3, unmet need for spacing was $6 \%$ and that for limiting was $7 \%$. Evidence from different surveys indicates that unmet need for family planning is higher in rural areas than urban areas. According to the study conducted in Bihar in 2012, the total unmet need for family planning was found to be $23.9 \%$; $9.4 \%$ for spacing birth and $14.5 \%$ for limiting birth. ${ }^{4}$ According to national statistics, in Kerala $50 \%$ are sterilized and $8 \%$ are practicing modern methods and yet another $11 \%$ are following natural methods. ${ }^{3}$ According to DLHS 3, in Malappuram district, unmet need for spacing is $11.4 \%$, for limiting is $8.3 \%$ and the total unmet need is $19.7 \%$. $^{5}$

The findings can be utilized to plan strategies for increasing contraceptive utilization.

The objective of this study was to assess the unmet need for family planning among married women of reproductive age group (15-49 years) in capital Perinthalmanna municipality. Also to find out the pattern of contraceptive practices and the reasons for not using contraceptive measures.

\section{METHODS}

A community based cross sectional study was conducted among married women in the reproductive age group of 15-49 years residing in 35 wards in Perinthalmanna municipality between April $8^{\text {th }}$ and June $6^{\text {th }} 2015$. Assuming the prevalence of unmet need as $19.7 \%$ from a district survey (DLHS 3) the sample size was calculated as 725 . Taking each ward as a cluster, 21 houses were covered in each of the 35 wards in 35 days by a team of 2 interns. From each ward the first house was selected randomly and thereafter consecutive houses were covered till about 21 married women of age group 15-49 years were interviewed. Only one married woman in the age group 15-49 years was interviewed from one house. A semi structured questionnaire was developed and it was pilot tested in the post natal ward of MES Medical College and then used for survey after necessary corrections were made. Data was analyzed by using epiinfo version 7. Institutional Ethical Committee clearance was obtained (IEC/MES/ 23/2015). Individual informed written consent was taken from each participant after assuring non-disclosure of identity.

For the study, unmet need was considered to be present if a pregnant or post-partum woman reported that her pregnancy was not wanted at that time or a fecund woman wanted to stop child birth or delay the next pregnancy but was not using any contraceptive methods. Women were assumed to be unfecund if they selfreported to be so or attained menopause or had hysterectomy. Women who reported using natural family planning successfully (no pregnancy for last five years) to delay pregnancy or whose husbands were abroad and later wanted a child birth was also excluded from the numerator.

\section{RESULTS}

A total of 753 married women in the age group 15-49 years were interviewed. Table 1 depicts the baseline details of the women interviewed and their husbands. The mean age of women was 30.94 years $(+7.277)$ and a little more than half $(53.9 \%)$ belonged to the age group 18-30 years. The mean age of husbands was 38.12 years (+8.579) ranging between 21 and 64. Half (51.66\%) the study participants had high school education and only $0.4 \%$ was illiterate. None of the husbands were illiterate and $45.29 \%$ had studied up to high school. Majority $(82.73 \%)$ of the participating women were home makers and most of the husbands were working.

The age at marriage of women in study ranged between 13-37 years with a mean of 19.77 years $(+3.53) .199$ (26.4\%) got married before the legal age of marriage and only $9(1.2 \%)$ got married after 30 years (Figure 1$)$. Table 2 shows the age at first child birth and it is seen that 104 $(15.8 \%)$ women gave birth to their first child before they were 18 years and only 7 after the age of $30.12 .6 \%$ (95) women did not have any children. Majority (606) had 1-3 children; only 9 had more than five children.

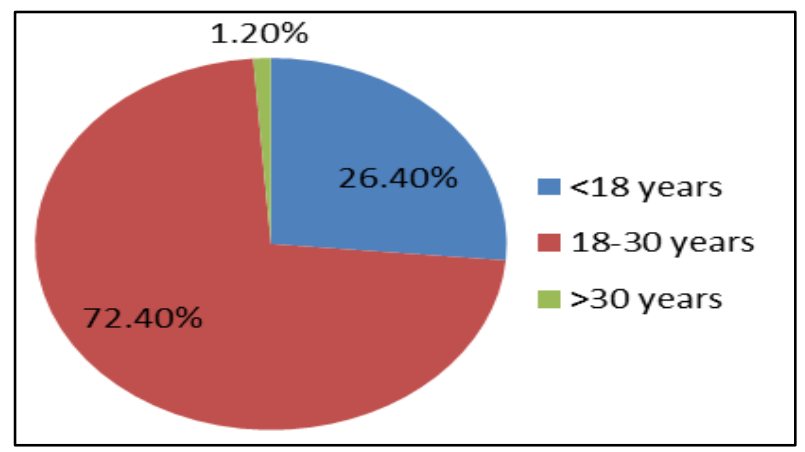

Figure 1: Age at marriage.

Out of 753 women in the study, 87 (11.55\%) were pregnant or post-partum at the time of study and 112 were not currently living together with their husbands as they are working at distant places or abroad. 
Table 1: Baseline characteristics of study participants and their husbands.

\begin{tabular}{|c|c|c|c|c|}
\hline \multicolumn{2}{|l|}{ Category } & \multicolumn{2}{|c|}{ Women (\%) } & \multirow{2}{*}{$\begin{array}{l}\text { Husbands (\%) } \\
\text { - }\end{array}$} \\
\hline \multirow{4}{*}{ Age group(years) } & $<18$ & $5(0.7)$ & $<21$ & \\
\hline & $18-30$ & $406(53.9)$ & $21-40$ & $505(67.1)$ \\
\hline & $31-45$ & $321(42.6)$ & $41-60$ & $247(32.8)$ \\
\hline & $>45$ & $21(2.8)$ & $>60$ & $1(0.1)$ \\
\hline \multirow{6}{*}{ Educational qualification } & Illiterate & $3(0.4)$ & & - \\
\hline & LP & $21(2.79)$ & & $27(3.59)$ \\
\hline & UP & 137 (18.19) & & $151(20.05)$ \\
\hline & HS & $389(51.66)$ & & $341(45.29)$ \\
\hline & Graduate & $185(24.57)$ & & $211(28.02)$ \\
\hline & PG & $18(2.39)$ & & $23(3.05)$ \\
\hline Home makers & & $625(83)$ & Unemployed & $1(0.1)$ \\
\hline \multirow{5}{*}{ Occupation } & Skilled & $39(5.2)$ & Skilled & $181(24)$ \\
\hline & Semi-skilled & $63(8.4)$ & Semi-skilled & $323(42.9)$ \\
\hline & Unskilled & $22(2.9)$ & Unskilled & $116(15.4)$ \\
\hline & Student & $4(0.5)$ & Retired & $1(0.1)$ \\
\hline & - & - & Abroad & $131(17.5)$ \\
\hline Total & & 753(100) & Total & $753(100)$ \\
\hline
\end{tabular}

Table 2: Age at which first child was born.

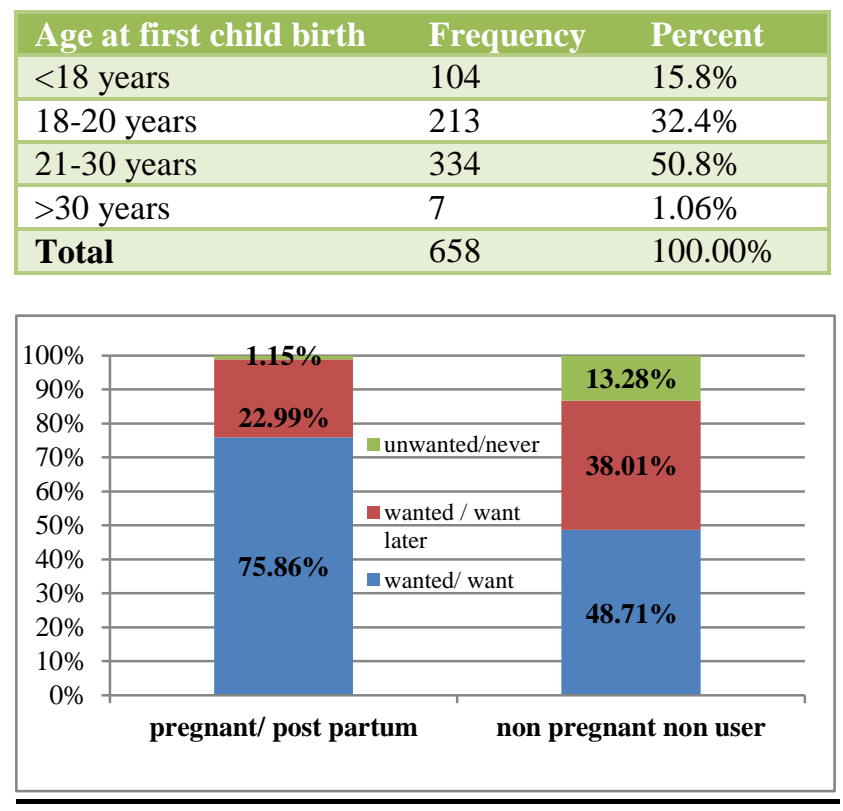

Figure 2: Reproductive intentions.

\section{Unmet need}

Figure 2 depicts the reproductive intentions of the study participants. Among the 753 women studied, 87 were pregnant or post-partum at the time of study. Among these 87 women, 20 wanted the pregnancy only at a later time giving an unmet need for spacing of $22.99 \%$. One woman reported she never wanted the pregnancy $(1.15 \%)$ giving a total unmet need of $24.1 \%$ for the current pregnancy. $66(77.01 \%)$ of these women informed that they wanted to have more children in future.

Table 3: Reasons for not using any contraceptives $(n=340)$.

\begin{tabular}{|lll|}
\hline Reason not using & Frequency & Percent \\
\hline Against faith & 26 & 7.6 \\
\hline Fear of complications & 36 & 10.6 \\
\hline Health doesn't permit & 1 & 0.3 \\
\hline Lack of knowledge & 23 & 6.8 \\
\hline $\begin{array}{l}\text { Opposition from family } \\
\text { members }\end{array}$ & 3 & 0.9 \\
\hline Opposition from partner & 20 & 5.9 \\
\hline Personal inconvenience & 5 & 1.5 \\
\hline Shame & 5 & 1.5 \\
\hline Preference for boy child & 11 & 3.2 \\
\hline Wanted more children & 30 & 8.8 \\
\hline
\end{tabular}

Among the 666 non-pregnant women, 326 (48.9\%) were using contraceptives. Among the remaining 340 nonpregnant women who were currently not using contraceptives, 69 were excluded from numerator as they were considered in fecund or not at risk of pregnancy as per working definition. Among the remaining fecund women, 103 wanted to delay their next pregnancy but are not using contraceptives for various reasons. 36 women informed that they wanted no more child births.

All together 123 women wanted to delay pregnancy but could not use any contraception, indicating unmet need 
for spacing of $16.3 \%$. Another 37 wanted to stop childbirth but could not achieve it indicating an unmet need for limiting of $4.9 \%$. The total unmet need was $21.2 \%$.

\section{Contraceptive practice}

Out of the 87 pregnant/ post-partum women, $30(34.48 \%)$ had ever used contraceptive measures prior to this pregnancy and $60(69 \%)$ women were planning to use contraceptive measures in future.

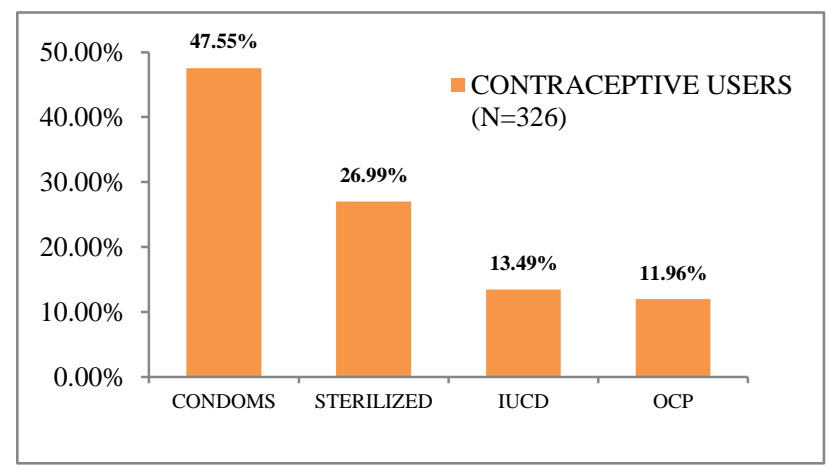

Figure 3: Methods of contraception practised.

Among the 112 women who are not currently living together with their husbands, one was pregnant; ten had undergone permanent sterilization and remaining 11 practiced temporary methods when living with husbands (2-condoms, 2-intrauterine devices, and 7-oral contraceptive pills) and 90 were not using any contraceptive measures.

Out of 666 non-pregnant women, half (48.95\%) were currently using some contraceptive method. Among 326 using contraceptives currently, majority (47.55\%) were using intra uterine contraceptive device (IUCD) like Copper $\mathrm{T} ; 44(13.49 \%)$ were using condoms and 39 $(11.96 \%)$ were taking oral contraceptive pills (OCP). About a quarter $(26.99 \%)$ had undergone permanent sterilization.

Among the 340 non pregnant women who are currently not using any contraceptives only 40 had ever used any contraceptive method. Most had used OCP (16 out of 40). $38.8 \%$ (132) wants to conceive now; $37.06 \%$ (126) responded they wanted to conceive later and $24.12 \%(82)$ did not want to conceive any more but still were not adopting any contraceptive measures.

\section{Reasons for non-acceptance of contraception}

More than half $(67.76 \%)$ replied they were practicing natural methods hence didn't feel other methods were needed. The commonest reason for not using any contraceptive method among women was fear of complications followed by reasons like contraception is against religious faith, opposition from husbands or senior family members and lack of knowledge. Other reasons were like preference for at least one boy child, shame and personal inconveniences. Some women gave more than one reason for not using any method (Table 3 ).

Table 4: Unmet need logistic regression stepwise model, (backward conditional).

\begin{tabular}{|lllll|}
\hline $\begin{array}{l}\text { Independent } \\
\text { variable }\end{array}$ & $\begin{array}{l}\text { Wald } \\
\text { statistic }\end{array}$ & Significance & $\begin{array}{l}\text { Adjusted } \\
\text { OR }\end{array}$ & $\begin{array}{l}95 \% \\
\text { CI }\end{array}$ \\
\hline $\begin{array}{l}\text { Woman's } \\
\text { age }\end{array}$ & 48.257 & 0.000 & 0.9 & $\begin{array}{l}0.873 \text { to } \\
0.927\end{array}$ \\
\hline $\begin{array}{l}\text { Woman's } \\
\text { educational } \\
\text { status }\end{array}$ & 3.896 & 0.048 & 0.604 & $\begin{array}{l}0.366 \text { to } \\
0.996\end{array}$ \\
\hline $\begin{array}{l}\text { Woman's } \\
\text { employment } \\
\text { status }\end{array}$ & 4.13 & 0.042 & 0.497 & $\begin{array}{l}0.253 \text { to } \\
0.975\end{array}$ \\
\hline
\end{tabular}

Entered variables: woman's age, educational status and employment status, age at marriage, husband's educational status and employment status.

\section{Factors influencing unmet need}

When association was looked for between total unmet need for family planning and certain characteristics of the woman like her age, education, occupation, age at marriage, total number of children and husband's age and his educational status; woman's age (p 0.049), her educational qualification ( $p$ 0.039), her occupational status ( $p$ 0.002) and the total number of children she has borne ( $p$ 0.001) were found to have significant association. We can see that as age increases the unmet need is decreasing. A woman having educational qualification below high school is shown to have higher unmet need. Similarly unmet need is more among the unemployed. On stepwise (backward conditional) logistic regression where woman's age, her age at marriage, her educational status (up to high school education or above) and employment status, her husband's educational status and employment status were entered as independent variables; woman's age, her educational status and employment status were found to have a significant effect on total unmet need for family planning (Table 4).

\section{DISCUSSION}

The unmet need for contraception in this urban area remains comparatively high $(21 \%)$ in spite of sufficient facilities available in the several hospitals functioning including government hospital. The unmet need is similar to the Bihar study (total unmet need-23.9\%; 9.4\%spacing; $14.5 \%$ - limiting). ${ }^{4}$ According to District Level Family health survey (DLHS 3), in Malappuram district, the total unmet need is $19.7 \%$ (11.4\% for spacing and $8.3 \%$ for limiting). ${ }^{5}$ But these results are higher than the result of national survey which reports $13 \% .^{3}$

Studies done in some underdeveloped African countries like Eastern Sudan, reports very high unmet need (total= $44.8 \%$; $15.1 \%$ for limiting and $0.7 \%$ for spacing). ${ }^{7}$ 
Another study in done in Botswana reports lower unmet need (total- 9.6\%; 6.7\% for limiting and $2.9 \%$ for spacing). ${ }^{8}$

Nearly half of women (48.9\%) were currently using contraceptives; which is lower compared to some other studies done in other parts of rural Kerala $(70.3 \%) .^{6}$ In a community based cross-sectional survey conducted in villages of Mukkam in Kerala, India during 2012-2013, $70.3 \%$ of women with mean age 33.29 years (SD 8.57) were practicing contraception at the time of study. ${ }^{6}$ In the Sudan study mentioned earlier, only $26.2 \%$ were current users and $25.4 \%$ had ever used. ${ }^{7}$

In our study, a quarter had undergone permanent sterilization. But in the study done in Mukkam, a rural area in another district of Kerala nearly half (49.9\%) had opted for permanent sterilization6 and $71 \%$ in NFHS-3. ${ }^{6}$

According to study conducted in Bihar, most common method ever used was IUCD $(41.2 \%)$, which was followed by OCP (32.1\%) and male condom $(23.3 \%){ }^{4}$ Among the $20.4 \%$ using temporary methods in rural Kerala study, $7.4 \%$ used condoms, $1.4 \%$ used OCPills and $1.1 \%$ had copper $\mathrm{T}$ inserted. ${ }^{6}$ In a study done in Lucknow, half $(53.4 \%)$ had IUCD inserted, $38.8 \%$ were having OCPills and $7.7 \%$ used condoms. ${ }^{9}$

The most common reason for not accepting contraception in Botswana study was health problems stated by $1 / 3^{\text {rd }}$ and $18.7 \%$ stated inconvenience. ${ }^{8}$ Partner opposition was stated by $12.2 \%$ only compared to $24.4 \%$ in our study showing that our women have less decision making power in such matters as regulating her own fertility. Partner's disapproval was stated by $34.2 \%$, lack awareness by $27.8 \%$ and fear side effects by $24.1 \%$ in the Bihar study. ${ }^{4}$ The most common reason was similar to the findings by population council that is fear of complications. ${ }^{10}$ These differences show that regional differences exist in reason for unmet need. The district of Malappuram including the area of our study has higher unmet need compared to other parts of Kerala. This may be because of the reason that till recently the district stood behind in education and employment especially of women.

In this study, woman's age, her educational status and employment status were found to have a significant effect on total unmet need for family planning. In Bihar study, unmet need varied significantly with age, with highest unmet need among less than 19 year old. ${ }^{4}$ Similarly, unmet need was higher in the lower income group and illiterates. In the Botswana study, unmet need was lesser among low parity and those aged 25-34 years. It was highest among uneducated and those aged 35-49 years. ${ }^{8}$ In a Bangladesh study, employment and age were found to be significant influencing factors whereas, current age, age at marriage and parity were found not to be associated in Sudan study. 7,11 There education of both woman and husband and her occupation played a role.

\section{CONCLUSION}

It could be concluded from our study that unmet need is high and the prevalence of contraceptive use in the study area in Perinthalmanna municipality is less than $50 \%$. In order to reduce this gap, we must consider the reasons for not using contraceptive measures and scale-up the program activities for reducing the unmet need. The study observations points towards the need for improving women's education, employment and their role in decision making.

\section{ACKNOWLEDGMENT}

The authors would like to thank Dr. Ashbeena Sulthana, Dr. Bestine Varghese, Dr. Dhanya krishanakumar, Dr. Dibiya Saleem, Dr. Farseena CK, Dr. Fayiza, Dr. Fifiya Yusuf, Dr. Indhu Krishnan, Dr. Haifa Sahib who did the data collection.

Funding: No funding sources

Conflict of interest: None declared

Ethical approval: The study was approved by the Institutional Ethics Committee

\section{REFERENCES}

1. UNFPA. Contraceptives save lives meeting the needs for family planning, 2009. Available at www.unfpa.org/safemotherhood.

2. Singh S, Darroch J. Adding it up: costs and benefits of family planning services, estimates for (New York: Guttmacher Institute; 2012.

3. Ministry of Health and Family Welfare. GOI. NFHS3: International Institute for population sciences (IIPS) and macro international. National Family Health Survey (NFHS-3); 2008.

4. Lata K, Barman SK, Ram R, Mukherjee S, Ram AK. Prevalence and determinants of unmet need for family planning in Kishanganj district, Bihar, India. GJMEDPH. 2012;1(4):29-33.

5. Ministry of Health and Family Welfare. GOI. DLHS3: International Institute for population sciences (iips) and macro international. District level family health survey -3 .

6. Anant TP, Annie J, Kumar D. Family planning practices in rural Kerala. Scholars Journal of Applied Medical Sciences. 2014;2(1A):19-21.

7. Aziem A, Ali A, Okud A. Factors affecting unmet need for family planning in Eastern Sudan. BMC Public Health. 2013;13:102.

8. Letamo G, Navaneetham K. Levels, trends and reasons for unmet need for family planning among married women in Botswana: a cross-sectional study. Department of population studies, faculty of social sciences, university of Botswana, Gaborone, Botswana. BMJ Open. 2015;5:e006603.

9. Kumar A, Bharadwaj P, Srivastava JP, Gupta P. A study on family planning practices and methods 
among women of urban slums of Lucknow city. IJCH. 2011;23(2):75-7.

10. The population council, Inc. 152. Reasons for contraceptive nonuse studies in family planning. 2014;45(2):151-169.
11. Uddin M, Ahmed T, Kibria M. Factors associated with unmet need of family planning and its impact on population growth in Bangladesh. Bangladesh Journal of Scientific Research. 2011.

12. Yadav K, Singh B, Goswami K. Indian journal of community medicine. 2009;34(3):188-91.

Cite this article as: Jesha MM, Sebastian NM, Haveri SP, Nath AS. Unmet needs for family planning in a municipal area in North Kerala, India. Int J Reprod Contracept Obstet Gynecol 2016;5:2322-7. 